\title{
Presentación Tema Central \\ Contradicciones de la renovación urbana en espacios centrales
}

\section{Presentation of the Central Theme Contradictions of urban renovation in central districts}

\author{
Angela Giglia \\ Universidad Autónoma Metropolitana Iztapalapa, \\ Ciudad de México, México
}

DoI: http://dx.doi.org/10.28928/revistaiztapalapa/802016/ptc/gigliaa

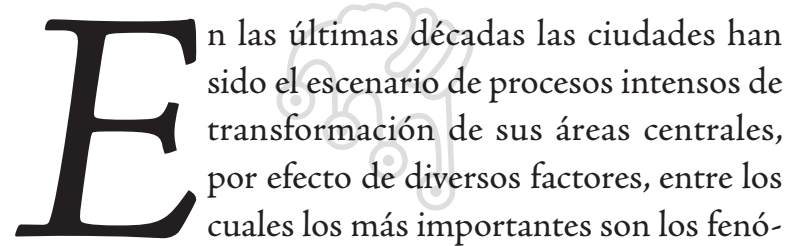

menos de recuperación y revalorización de los centros históricos asociados a proyectos de patrimonialización, y la construcción de proyectos inmobiliarios de usos mixtos (residencial y de servicios) especialmente para clases medias y altas en zonas provistas de ubicaciones privilegiadas. En términos generales estos cambios dinamizan y complejizan la experiencia urbana de las ciudades y son reflejo de las formas de producción del espacio en la cual los capitales nacionales e internacionales se involucran cada vez de manera más decidida. En términos de su impacto a nivel local, diversos autores han evidenciado que estos fenómenos de revalorización de la llamada ciudad central tienden a generar una metrópoli cada vez más dividida y desigual, incrementando la calidad del entorno construido de una parte reducida de la ciudad mientras se acrecienta la 
distancia y la polarización con respecto al territorio urbano que por diversas razones queda fuera o al margen de los procesos de renovación, configurándose de este modo una ciudad de dos caras: unas áreas centrales provistas de infraestructuras y servicios urbanos de buena calidad y comparables a los de otras grandes capitales del mundo; y una corona de territorios periféricos constituidos por asentamientos provistos de servicios escasos y muy precarios hasta en los más básicos como, por ejemplo, el suministro de agua corriente, y que además se encuentran a menudo alejados y desconectados del resto del tejido urbano.

Los espacios centrales renovados, ya sea como resultado de la recuperación de áreas históricas, o bien como nuevos proyectos inmobiliarios, tienden a funcionar como polos de atracción para ciertos habitantes y al mismo tiempo se convierten en lugares excluyentes para otros habitantes, generalmente de menores ingresos o en posición de marginalidad, cuya presencia no es considerada acorde con la nueva imagen de los lugares. De este modo, mientras algunos habitantes se apropian de los nuevos espacios, los disfrutan y generan nuevos modos de habitar y nuevos significados del espacio local, otros son empujados fuera de los perímetros revalorizados, ya sea por la vía del mercado, es decir, mediante el aumento de los precios de la vivienda, o por efecto de políticas expresamente dirigidas a la expulsión de determinadas poblaciones, como es el caso de los vendedores ambulantes y los indigentes en todos los principales centros históricos. Estas poblaciones marginadas que solían encontrar en el espacio público un medio donde estar y un recurso para su supervivencia cotidiana, ahora tienden a ser alejadas de los espacios revalorizados mediante diversos mecanismos disuasivos que merman su derecho de estar presentes en el espacio público urbano. La tendencia general consiste en convertir los espacios revalorizados en el escenario ideal para el consumo de la experiencia urbana a través de grandes artefactos arquitectónicos con funciones recreativas y comerciales o por medio de la conversión de los centros históricos en museos al aire libre donde el turismo nacional e internacional pueda disfrutar de una oferta cultural y recreativa que retroalimente la promoción de la ciudad como marca.

Sin embargo, el conjunto de estos procesos, que algunos tienden a resumir bajo la etiqueta de la gentrificación como un fenómeno de sustitución de población de menores recursos por habitantes de niveles más altos, no se configura como algo lineal y homogéneo. La exploración que se presenta en este número de Iztapalapa. Revista de Ciencias Sociales y Humanidades, referente a algunos casos de renovación urbana en áreas centrales de la Ciudad de México y San Luis Potosí, pretende mostrar un panorama diversificado de las tensiones y las contradicciones internas a estos fenómenos. La revalorización de espacios centrales es un fenómeno complejo, 
que contempla también procesos de adaptación y resistencia, dirigidos a afirmar el derecho de las poblaciones afectadas a estar presentes en los espacios renovados. De allí el interés por estudiar las tensiones y disputas que acompañan los diversos usos de los espacios urbanos sometidos a procesos de renovación.

El primero de los textos sobre este tema, escrito por Claudia Gasca, se refiere a la reciente transformación de algunas áreas del Centro Histórico de la ciudad de San Luis Potosí, un caso muy ilustrativo de lo que puede implicar para un espacio central de una ciudad mediana llegar a ser considerado por la unesco como Patrimonio Histórico, con los consecuentes proyectos de revalorización y las perspectivas de especulación inmobiliaria. Resultado de una amplia y prolongada investigación, este trabajo se enfoca sobre las prácticas espaciales de diversos habitantes de zonas céntricas, examinadas tomando en cuenta el arraigo local y la pertenencia electiva, conceptos que designan la generación del apego al lugar que se produce no tanto desde la tradición y el tiempo de permanencia como desde su elección como espacio acorde con la imagen de sí mismo y el lugar del sujeto en la sociedad y en la urbe (Savage M. et al., 2005). El trabajo resalta la creatividad de dichas prácticas, las cuales le confieren a los espacios habitados un sentido colectivo que va mucho más allá del sentido que se quiere promover desde las políticas de valorización turística del centro, respecto de las cuales los habitantes han sido dejados de lado, sin un verdadero proyecto de involucramiento para tomar en cuenta sus modos de vida y sus necesidades en los planes de valorización turísticas del centro histórico. De allí que algunos habitantes se sientan ajenos en su propio espacio, al que ven sometido a cambios sobre los cuales no tienen el menor control ni la posibilidad de ser escuchados. Otros habitantes, en cambio, que han elegido vivir en el centro como una forma innovadora de estar en la ciudad, se muestran más optimistas acerca de las posibilidades de enriquecer y diversificar las condiciones de habitabilidad del centro urbano.

En una línea de reflexión semejante, pero enfocado en otro contexto y con otros actores sociales, el artículo de Marcela Meneses analiza las dinámicas de resistencia de los habitantes indígenas del Centro Histórico de la Ciudad de México a partir de los cambios generados por la renovación y revalorización de la Alameda Central, uno de los parques más antiguos e importantes en América Latina, que ha sido transformado en un atractivo turístico de primer plano en el marco de la patrimonialización y remodelación de amplias áreas de esa zona de la ciudad. Este trabajo presenta un recuento puntual del proceso de remodelación vinculándolo con sus antecedentes, y muestra de este modo la persistencia de la postura de las autoridades citadinas en cuanto a los buenos usos y a los usuarios no deseados de 
la Alameda, que se mantienen desde hace tres siglos como ahora. Y expone también, a partir de un enfoque etnográfico, las prácticas de resistencia de los jóvenes indígenas, quienes después de unos meses han vuelto a la Alameda como a uno de sus lugares preferidos de socialización y diversión de fin de semana, reivindicando de este modo en los hechos, más que con discursos, su derecho a hacerse presentes y a habitar el espacio del centro de la ciudad.

El texto de María Teresa Esquivel, en seguida, analiza la situción de vivienda de familias de sectores populares que siguen habitando en el Centro histórico de la Ciudad de México gracias al Programa de Renovación Habitacional Popular, el cual hizo posible la permanencia ahí de 40000 familias arrendatarias de cuartos o inmuebles deteriorados después del terremoto de 1985. A contracorriente respecto de las tendencias en auge, estas familias se volvieron propietarias de una vivienda económica en pequeñas unidades habitacionales ubicadas en sus mismos barrios, como resultado de la intervención institucional y de la presión de la sociedad civil organizada de la época. El principio inspirador del programa fue reafirmar el derecho de los habitantes de bajos recursos a permanecer en sus barrios y a no ser expulsados por efecto de las fuerzas del libre mercado que encarecen cada vez más los espacios centrales. Los resultados de este programa, después de 25 años, no están exentos de contradicciones. Por un lado es considerable la cantidad de personas que efectivamente pudieron permanecer en su vivienda en una ubicación favorable. Pero, por otro lado, la mala calidad de la construcción y los problemas relativos a la gestión colectiva de los espacios condominales han restado valor a esas propiedades y han repercutido negativamente sobre la habitabilidad de estos lugares y la posibilidad de vender la vivienda para mudarse a otro lado. Nos encontramos entonces con la paradoja de habitantes de bajos recursos que se enfrentan a una situación ambivalente: arraigados en el centro por una parte, pero imposibilitados para moverse, por la otra.

Finalmente, el cuarto artículo, escrito por Adriana Aguayo, relata y analiza el caso de un proyecto de renovación urbana de gran envergadura llevado a cabo en la Ciudad de México, en un área que fue industrial hasta hace dos décadas, y que en años recientes ha sido destinada a hospedar un gran número de desarrollos inmobiliarios que incluyen, todos en diversas dosis, una combinación de vivienda de lujo, oficinas y comercios de alta gama, junto con algunos otros servicios, en la lógica de generar una suerte de espacio autosuficiente, similar a una ciudad dentro de la ciudad. Se trata del área conocida como Nuevo Polanco, la cual desde el nombre pretende autoatribuirse algo del glamour de un barrio residencial de clase alta con una muy consolidada tradición, como es la colonia Polanco. Este texto nos muestra algunos de los efectos más recurrente de este tipo de desarrollo sobre su entorno, 
tales como la autosegregación de algunos sectores de población y la expulsión de otros, que ya no pueden sostenerse en un entorno profundamente trastocado en términos económicos y urbanístico-arquitectónicos. Los dos mundos, el anterior a la llegada del megaproyecto y el que este ha llegado a producir, parecen vivir en tiempos y espacios que no se comunican; sin embargo, pueden resultar en algunos casos fuertemente interdependientes, en la medida en que los sectores de clase alta necesitan a la población autóctona para los servicios domésticos y el abasto diario. Se hace evidente así la complejidad de los modos de vida generados por los cambios inmobiliarios y la separación y acentuación de las desigualdades que derivan de la lógica de las ganancias inmobiliarias cuando estas no encuentran un control adecuado en las normas de planificación urbana y su implementación.

\section{Bibliografía}

Harvey David (200I) Spaces of Capital, Edimburgo, Edimburg University Press. Savage M., G. Bagnall y B. Longhurst (2005), Globalization and Belonging, Londres, Sage. 